\title{
CrimRxiv
}

\section{Asymmetry in Psychoactive Research: A Bibliometric Study on 15 Psychoactive Drugs}

Julia Lebrero-Tatay, Arthur Sebag, Ivan Ezquerra-Romano

Published on: Feb 16, 2022

DOI: $10.21428 / c b 6 a b 371.7 d a d 6 b 43$

License: Creative Commons Attribution 4.0 International License (CC-BY 4.0). 
